Check for updates

London, UK

Cite this as: $B M J$ 2021;374:n1686 http://dx.doi.org/10.1136/bmj.n1686 Published: 02 July 2021

\title{
Covid-19: Millions could be offered booster vaccinations from September
}

Shaun Griffin

Covid-19 booster vaccinations should be offered in England from September 2021, the Joint Committee on Vaccination and Immunisation has advised. But some experts have questioned the necessity and the practicalities of the plan.

JCVI's interim advice, ${ }^{1}$ which will be updated by September after further data analysis, could lead to millions of the people who are most vulnerable to covid-19 being offered the booster vaccination in a two stage approach alongside the annual flu vaccination programme.

JCVI advised that in the first stage a third dose of covid-19 booster and annual flu vaccine should be offered as soon as possible from September 2021 to immunosuppressed adults aged 16 or over, people living in residential care homes for older adults, all adults aged 70 years or over, clinically extremely vulnerable adults aged 16 or over; and frontline health and social care workers.

The second stage would see the covid booster vaccine being offered as soon as possible after stage 1 to all adults aged 50 or over, people aged 16-49 in groups at risk of serious illness from flu or covid-19, and adult household contacts of immunosuppressed people. There would be an equal emphasis on deployment of the flu vaccine, where eligible, in these groups, said JCVI.

David Elliman, a consultant in community child health at Whittington NHS Trust in London, said that more data were needed before the programme is rolled out. "At the moment there is little clinical or laboratory evidence that boosters are needed, and JCVI has understandably not committed itself yet. If a booster is needed, exactly how much benefit would it give and would it justify the resources?" he asked.

JCVI said its final advice will take into account data on vaccine safety, efficacy, and durability over time, the latest epidemiological evidence, and information on emerging variants and results of clinical trials. ${ }^{2}$

Elliman also questioned the value of providing booster vaccination for all adults aged over 50, "at the expense of others for whom there would be much greater benefit ... when, in large parts of the world, there is not enough vaccine to give one dose to the adult population."

\section{"Spreading capacity" across primary care}

On 1 July NHS England issued provisional guidance to local leaders stating that, although further data were expected, "the core planning scenario systems should prepare to deliver booster doses of covid-19 vaccine to the individuals outlined . . . between 6 September and 17 December 2021 (15 weeks).”3
NHS England said local systems should seek to spread capacity across community pharmacies, vaccination centres, and general practices so as to "provide resilience and ease pressure on other services and workforces," adding, "For most areas it may be hard for general practice to deliver more than around $75 \%$ of vaccinations, based on learnings from phase 1." It said that in most cases local systems should "prudently plan for a minimum of $40 \%$ of covid-19 booster vaccination through general practice and a maximum of $75 \%$."

Richard Vautrey, chair of the BMA's General Practitioners Committee, said it was good that JCVI was already discussing administering covid booster jabs in the same appointment as flu vaccines but questioned the advice to limit GPs' involvement. "Given the achievements of the first round of vaccinations, it makes no sense for NHS England to suggest limiting the proportion of vaccines delivered locally by practice sites-and we'd be concerned that this will be interpreted as a cap on general practice's involvement in the programme and placing barriers in the way of patients being vaccinated by their local, trusted surgery team," he said.

Martin Marshall, chair of the Royal College of General Practitioners, urged the government to provide clarity on exactly what the role of general practice would likely to be "as a matter of urgency, so that plans and decisions can be made appropriately."

Ravi Sharma, the Royal Pharmaceutical Society's director for England, called for the "widespread involvement of community pharmacy in delivering the covid booster jab and flu jab together for the over 50s, and appropriate funding to ensure this service can be delivered, including a collaboration between pharmacy and general practice.”

JCVI interim advice: potential COVID-19 booster vaccine programme winter 2021 to 2022. 30 June 2021. https://www.gov.uk/government/publications/icvi-interim-advice-on-a-potential-coronavirus-covid-19-boostervaccine-programme-for-winter-2021-to-2022/jcvi-interim-advice-potentialcovid-19-booster-vaccine-programme-winter-2021-to-2022.

2 World first COVID-19 vaccine booster study launches in UK. 20 May 2021. https://www.gov.uk/government/news/world-first-covid-19-vaccinebooster-study-launches-in-uk-2.

3 Dear colleagues covid-19 vaccination autumn / winter (phase 3) planning. https://www.england.nhs.uk/coronavirus/wp-content/up-

loads/sites/52/2021/07/C1327-covid-19-vaccination-autumn-winter-phase3-planning.pdf.

This article is made freely available for use in accordance with BMJ's website terms and conditions for the duration of the covid-19 pandemic or until otherwise determined by BMJ. You may use, download and print the article for any lawful, non-commercial purpose (including text and data mining) provided that all copyright notices and trade marks are retained. 